\section{JURNAL EKONOMI EFEKTIF}

ISSN : $2622-8882$, E-ISSN : 2622-9935

Jurnal Ekonomi Efektif, Vol. 2, No. 4, Juli 2020

@)Prodi Manajemen Fakultas Ekonomi Universitas

Pamulang

\title{
PENGARUH BUDAYA ORGANISASI TERHADAP KINERJA KARYAWAN PADA PT. LANGGENG KENCANA DI JAKARTA
}

\section{Tarwijo}

\author{
Universitas Pamulang, Tangerang Selatan, Banten, Indonesia \\ *dosen01476@unpam.ac.id
}

\begin{abstract}
ABSTRAK
Penelitian ini bertujuan untuk mengetahui pengaruh budaya organisasi terhadap kinerja karyawan pada PT. Langgeng Kencana di Jakarta. Metode yang digunakan adalah explanatory research dengan sampel sebanyak 96 responden. Teknik analisis menggunakan analisis statistik dengan pengujian regresi, korelasi, determinasi dan uji hipotesis. Hasil penelitian ini variabel budaya organisasi diperoleh nilai rata-rata skor sebesar 3,493 dengan kriteria baik. Variabel kinerja karyawan diperoleh nilai rata-rata skor sebesar 3,796 dengan kriteria baik. Budaya organisasi berpengaruh positif dan signifikan terhadap kinerja karyawan dengan nilai persamaan regresi $\mathrm{Y}=12,482+0,729 \mathrm{X}$, dan nilai koefisien korelasi 0,742 atau memiliki tingkat hubungan yang kuat dengan nilai determinasi 55,1\%. Uji hipotesis diperoleh signifikansi $0,000<0,05$.
\end{abstract}

\section{Kata Kunci: Budaya Organisasi, Kinerja Karyawan.}

\section{ABSTRACT}

This study aims to determine the effect of organizational culture on employee performance at PT. Langgeng Kencana in Jakarta. The method used is explanatory research with a sample of 96 respondents. The analysis technique uses statistical analysis with regression testing, correlation, determination and hypothesis testing. The results of this study, the organizational culture variable obtained an average score of 3.493 with good criteria. Employee performance variables obtained an average score of 3,796 with good criteria. Organizational culture has a positive and significant effect on employee performance with a regression equation value of $Y=12.482+0.729 X$, and a correlation coefficient value of 0.742 or has a strong level of relationship with a determination value of $55.1 \%$. Hypothesis testing obtained a significance of $0.000<0.05$.

Keywords: Organizational Culture, Employee Performance. 


\section{PENDAHULUAN}

\section{A. Latar Belakang Masalah}

Dalam suatu organisasi peranan sumber daya manusia merupakan komponen utama yang menjadi perencanaan dan pelaku aktif dalam setiap aktifitas organisasi. Masalah sumber daya manusia merupakan aspek yang paling penting bagi kelangsungan hidup suatu perusahaan. Bila aspek ini melemah tentunya tujuan dari perusahaan tidak akan tercapai secara efektif dan efisien.

Kecenderungan global yang semakin kompetitif tersebut berpengaruh kuat pada budaya organisasi. Budaya dalam suatu organisasi, baik organisasi pemerintahan maupun swasta mencerminkan penampilan organisasi, bagaimana organisasi dilihat oleh orang yang berada di luarnya. Organisasi yang mempunyai budaya positif akan menunjukkan citra positif pula, demikian pula sebaliknya, apabila budaya organisasi tidak berjalan baik akan memberikan citra negatif bagi organisasi.

Budaya organisasi merupakan sebuah persepsi umum yang dipegang oleh anggota organisasi, suatu sistem tentang keberartian bersama. (Robbins dalam Wibowo, 2016:15. Perubahan budaya organisasi menyebabkan kegelisahan bagi banyak karyawan Gogirl! Magazine, menyebabkan konflik antara mereka yang merasa menjadi "winner dan loser" atau antara kelompok "kita atau mereka". Namun, bagi karyawan yang berpikiran progresif, perubahan budaya organisasi membuka kesempatan baru untuk kreativitas, individualitas, inovasi, dan hubungan.

Konflik tersebut ditunjukkan dengan pekerjaan yang terlihat kurang efisien. Banyak karyawan yang tidak dapat memanfaatkan waktu kerja di siang hari dengan baik, akibatnya mereka terlalu sering lembur hingga malam dikarenakan mengejar deadline yang telah ditetapkan setiap bulannya. Karena mereka yang bekerja di bagian redaksi beralasan bahwa terkadang inspirasi baru didapatkan pada malam hari. Padahal hal itu mengakibatkan membengkaknya biaya operasional perusahaan tiap bulannya.

Kenyataan menunjukkan banyak organisasi yang mengalami kemunduran karena ketidakmampuannya menyesuaikan diri dengan perubahan lingkungan. Perubahan budaya diperlukan paling tidak untuk dapat bertahan terhadap goncangan yang timbul sebagai akibat dari perubahan lingkungan.

Untuk bertahan terhadap lingkungan yang menantang di masa depan, Gogirl! Magazine perlu membicarakan masalah budaya organisasi. Organisasi tidak lagi dapat mengusahakan solusi dalam jangka pendek atau secara cepat. Mengembangkan budaya organisasi yang benar akan memerlukan waktu lebih lama untuk brainstorming. Diperlukan komitmen jangka panjang untuk menanamkan perlunya core values dan mendapatkan orang mempraktikan secara spesifik perilaku untuk mendapatkan budaya dan hasil yang diinginkan, tetapi usaha yang dilakukan akan berharga. Penelusuran akan perlunya perubahan budaya organisasi harus dilakukan sejak dini, karena proses perubahan budaya akan memerlukan waktu lama untuk memberikan hasil. Semakin lama organisasi menunggu untuk menjalankan proses, maka semakin sulit tugas.

Suatu organisasi dibentuk untuk mencapai suatu tujuan tertentu. Tujuan adalah sesuatu yang diharapkan organisasi untuk dicapai. Tujuan organisasi dapat berupa perbaikan pelayanan pelanggan, pemenuhan permintaan pasar, peningkatan kualitas produk atau jasa, meningkatnya daya saing, dan meningkatnya kinerja karyawan.

Sebagaimana diketahui, kinerja karyawan adalah hasil kerja yang dicapai seseorang dalam melaksanakan tugas-tugas yang dibebankan kepadanya didasarkan atas kecakapan, pengalaman, kesungguhan, serta waktu. (Hasibuan, 2012:231). Keberhasilan suatu organisasi sangat erat kaitannya dengan kualitas kerja para anggotanya, sehingga organisasi dituntut untuk selalu mengembangkan dan meningkatkan kinerja dari para 
anggotanya. Kinerja karyawan berarti hasil kerja yang dapat ditampilkan atau penampilan kerja seseorang karyawan. Dengan demikian kinerja seorang karyawan dapat diukur dari hasil kerja, hasil tugas, atau hasil kegiatan dalam kurun waktu tertentu. (Notoatmodjo, 2015:124)

Kinerja yang dimiliki oleh karyawan PT. Langgeng Kencana masih belum optimal. Karyawan kurang semangat bekerja karena merasa kebutuhan baik fisik dan non fisik belum terpenuhi. Padahal kinerja perusahaan sangat ditentukan oleh kinerja karyawan yang menjadi ujung tombak kantor itu.

Seorang karyawan memiliki andil atas setiap pekerjaan yang diberikan oleh perusahaan. Namun masih banyak karyawan yang belum mampu untuk menyelesaikan pekerjaan dengan baik. Terkadang masalah itu terjadi karena kurangnya loyalitas dan rasa memiliki atas perusahaan.

Rendahnya kemampuan kerja secara cermat dan teliti juga merupakan masalah lain dalam PT. Langgeng Kencana. Karyawan bekerja secara apa adanya dengan asumsi bahwa para atasan divisi akan dapat mengecek sekaligus memperbaiki setiap hasil kerja anak buahnya. Padahal hal tersebut dapat membuat target waktu penyelesaian pekerjaan tidak tercapai. Dan berakibat pula pada membengkaknya biaya operasional pendukung suatu proyek yang sedang dikerjakan seperti pembayaran lembur karyawan setiap bulannya.

Selain hal tersebut di atas, kinerja karyawan juga dapat dilihat dari hasil kerja yang dihasilkan dalam satu waktu periode tertentu. Perusahaan telah menetapkan target yang telah disepakati pada saat Rapat Kerja Tahunan. Namun beberapa divisi belum dapat mencapai target tersebut dikarenakan hal-hal dari luar maupun dalam perusahaan.

Berdasarkan latar belakang permasalahan di atas maka Penulis mengambil judul "Pengaruh Budaya Organisasi Terhadap Kinerja Karyawan Pada PT. Langgeng Kencana di Jakarta".

\section{B. Rumusan Masalah}

1. Bagaimana budaya organisasi pada PT. Langgeng Kencana di Jakarta ?.

2. Bagaimana kinerja karyawan pada PT. Langgeng Kencana di Jakarta ?.

3. Adakah pengaruh antara budaya organisasi terhadap kinerja karyawan pada PT. Langgeng Kencana di Jakarta?.

\section{Tujuan Penelitian}

1. Untuk mengetahui kondisi budaya organisasi pada PT. Langgeng Kencana di Jakarta.

2. Untuk mengetahui kondisi kinerja karyawan pada PT. Langgeng Kencana di Jakarta.

3. Untuk mengetahui pengaruh antara budaya organisasi terhadap kinerja karyawan pada PT. Langgeng Kencana di Jakarta.

\section{TINJAUAN PUSTAKA}

\section{Budaya Organisasi}

Menurut Hairiyah (2017:11) mengemukanan "Budaya organisasi adalah sekelompok asumsi penting (yang sering kali tidak dinyatakan jelas) yang dipegang bersama oleh anggota-anggota dalam suatu organisasi". Budaya organisasi adalah sehimpunan nilai, prinsip-prinsip, tradisi, dan cara-cara bekerja yang dianut bersama oleh para anggota organisasi dan mempengaruhi cara mereka bertindak". Dengan demikian budaya organisasi merupakan kultur yang mengandung apa yang boleh dilakukan atau tidak boleh dilakukan sehingga dapat dikatakan sebagai suatu pedoman sehingga budaya organisasi dalam perusahaan juga merupakan alat untuk mempersatukan setiap individu yang melakukan 
aktivitas secara bersama-sama atau secara tim.

\section{Kinerja Karyawan}

Menurut Wibowo (2016:18) "Kinerja merupakan hasil pekerjaan yang mempunyai hubungan kuat strategis organisasi, kepuasan kenosumen dan memberikan kontribusi ekonomi". Sedangkan menurut Ratundo dan Sacket (2016:76) mendefinisikan "Kinerja adalah kegiatan yang mencakup semua tindakan atau perilaku yang dikontrol oleh individu dan memberi kontribusi pada pencapaian tujuan-tujuan perusahaan". Pendapat serupa juga dikemukakan oleh Hariandja (2017:55) yang mengemukakan "Kinerja merupakan hasil kerja yang dihasilkan oleh karyawan atau karyawan atau perilaku nyata yang ditampilkan sesuai dengan perannya dalam organisasi. Mathis (2016:113) berpendapat "Kinerja adalah apa yang dilakukan atau tidak dilakukan oleh karyawan”.

\section{METODE PENELITIAN}

\section{Populasi}

Populasi dalam penelitian ini berjumlah 96 responden PT. Langgeng Kencana di Jakarta

\section{Sampel}

Teknik pengambilan sampling dalam penelitian ini adalah sampel jenuh, dimana semua anggota populasi dijadikan sebagai sampel. Dengan demikian sampel dalam penelitian ini sampel yang digunakan berjumlah 96 responden.

\section{Jenis Penelitian}

Jenis penelitian yang dipakai adalah asosiatif, dimana tujuannya adalah untuk mengetahui atau mencari keterhubungan antara variabel independen terhadap variabel dependennya

\section{Metode Analisis Data}

Dalam menganalisis data digunakan uji validitas, uji reliabilitas, analisis regresi linier sederhana, analisis koefisien korelasi, analisis koefisien determinasi dan pengujian hipotesis.

\section{HASIL PENELITIAN}

\section{Analisis Deskriptif}

Pada pengujian ini digunakan untuk mengetahui skor minimum dan maksimum skor tertinggi, ratting score dan standar deviasi dari masing-masing variabel. Adapun hasilnya sebagai berikut:

Tabel 1. Hasil Analisis Descriptive Statistics

\begin{tabular}{l|r|r|r|r|r}
\multicolumn{7}{c}{ Descriptive Statistics } \\
& N & Minimum & Maximum & Mean & Std. Deviation \\
\hline Budaya organisasi $(\mathrm{X})$ & 96 & 29 & 48 & 34.93 & 3.993 \\
\hline Kinerja Karyawan $(\mathrm{Y})$ & 96 & 29 & 49 & 37.96 & 3.923 \\
\hline Valid N (listwise) & 96 & & & & \\
\hline
\end{tabular}

Budaya organisasi diperoleh varians minimum sebesar 29 dan varians maximum 48 dengan ratting score sebesar 3,493 dengan standar deviasi 3,993. Skor ini termasuk pada rentang sakala 3,40 - 4,19 dengan kriteria baik atau setuju.

Kinerja karyawan diperoleh varians minimum sebesar 29 dan varians maximum 49 dengan ratting score sebesar 3,796 dengan standar deviasi 3,923. Skor ini termasuk pada rentang sakala 3,40-4,19 dengan kriteria baik atau setuju. 


\section{Analisis Verifikatif.}

Pada analisis ini dimaksudkan untuk mengetahui pengaruh variabel independen terhadap variabel dependen. Adapun hasil pengujian sebagai berikut:

\section{a. Analisis Regresi Linier Sederhana}

Uji regresi ini dimaksudkan untuk mengetahui perubahan variabel dependen jika variabel independen mengalami perubahan. Adapun hasil pengujiannya sebagai berikut:

Tabel 2. Hasil Pengujian Regresi Linier Sederhana

\begin{tabular}{lr|r|r|r|r} 
& \multicolumn{2}{c}{ Coefficients $^{\mathbf{a}}$} \\
& $\begin{array}{c}\text { Unstandardized } \\
\text { Coefficients }\end{array}$ & $\begin{array}{c}\text { Standardized } \\
\text { Coefficients }\end{array}$ & & \\
Model & \multicolumn{1}{c}{ B } & Std. Error & Beta & \multicolumn{1}{c}{ t } & \multicolumn{1}{c}{ Sig. } \\
\hline 1 (Constant) & 12.482 & 2.386 & & 5.231 & .000 \\
\hline Budaya organisasi (X) & .729 & .068 & .742 & 10.745 & .000 \\
\hline
\end{tabular}

Berdasarkan hasil pengujian pada tabel di atas, diperoleh persamaan regresi $\mathrm{Y}=$ $12,482+0,729 X$. Dari persamaan tersebut dijelaskan sebagai berikut:

1) Konstanta sebesar 12,482 diartikan jika budaya organisasi tidak ada, maka telah terdapat nilai kinerja karyawan sebesar 12,482 point.

2) Koefisien regresi budaya organisasi sebesar 0,729 , angka ini positif artinya setiap ada peningkatan budaya organisasi sebesar 0,729 point maka kinerja karyawan juga akan mengalami peningkatan sebesar 0,729 point.

\section{b. Analisis Koefisien Korelasi}

Analisis koefisien korelasi dimaksudkan untuk mengetahui tingkat kekuatan hubungan dari variabel independen terhadap variabel dependen. Adapun hasil pengujian sebagai berikut:

Tabel 3. Hasil Pengujian Koefisien Korelasi Budaya organisasi Terhadap Kinerja Karyawan.

\begin{tabular}{|c|c|c|c|}
\hline \multicolumn{4}{|c|}{ Correlations $^{b}$} \\
\hline & & $\begin{array}{c}\text { Budaya } \\
\text { organisasi }(X 1)\end{array}$ & $\begin{array}{c}\text { Kinerja Karyawan } \\
(Y)\end{array}$ \\
\hline \multirow[t]{2}{*}{ Budaya organisasi $(\mathrm{X})$} & Pearson Correlation & 1 & $.742^{* \star}$ \\
\hline & Sig. (2-tailed) & & .000 \\
\hline \multirow[t]{2}{*}{ Kinerja Karyawan (Y) } & Pearson Correlation & $.742^{* *}$ & 1 \\
\hline & Sig. (2-tailed) & .000 & \\
\hline
\end{tabular}

Berdasarkan hasil pengujian diperoleh nilai korelasi sebesar 0,742 artinya budaya organisasi memiliki hubungan yang kuat terhadap kinerja karyawan.

\section{c. Analisis Koefisien Determinasi}

Analisis koefisien determinasi dimaksudkan untuk mengetahui besarnya persentase pengaruh dari variabel independen terhadap variabel dependen. Adapun hasil pengujian sebagai berikut:

Tabel 4. Hasil Pengujian Koefisien Determinasi Budaya organisasi Terhadap Kinerja Karyawan.

\begin{tabular}{|c|c|c|c|c|}
\hline \multicolumn{5}{|c|}{ Model Summary } \\
\hline Model & $\mathrm{R}$ & R Square & $\begin{array}{l}\text { Adjusted R } \\
\text { Square }\end{array}$ & $\begin{array}{l}\text { Std. Error of the } \\
\text { Estimate }\end{array}$ \\
\hline 1 & $.742^{\mathrm{a}}$ & .551 & .546 & 2.642 \\
\hline
\end{tabular}

Berdasarkan hasil pengujian diperoleh nilai determinasi sebesar 0,551 artinya budaya organisasi memiliki kontribusi pengaruh sebesar $55,1 \%$ terhadap kinerja 
karyawan, sedangkan sisanya sebesar $44,9 \%$ dipengaruhi oleh faktor lain yang tidak dilakukan penelitian.

\section{d. Uji Hipotesis}

Pengujian hipotesis dengan uji t digunakan untuk mengetahui hipotesis mana yang diterima.

Rumusan hipotesis: Terdapat pengaruh yang signifikan antara budaya organisasi terhadap kinerja karyawan.

Tabel 5. Hasil Uji Hipotesis Budaya organisasi Terhadap Kinerja Karyawan.

\begin{tabular}{|c|c|c|c|c|c|}
\hline \multirow[b]{2}{*}{ Model } & $\begin{array}{l}\text { Co } \\
\text { Unst } \\
\text { Co }\end{array}$ & $\begin{array}{l}\text { ficients }^{\text {a }} \\
\text { idardized } \\
\text { ficients }\end{array}$ & \multirow{2}{*}{$\begin{array}{c}\text { Standardized } \\
\text { Coefficients } \\
\text { Beta }\end{array}$} & \multirow[b]{2}{*}{$\mathrm{t}$} & \multirow[b]{2}{*}{ Sig. } \\
\hline & B & Std. Error & & & \\
\hline 1 (Constant) & 12.482 & 2.386 & & 5.231 & .000 \\
\hline Budaya organisasi (X) & .729 & .068 & .742 & 10.745 & .000 \\
\hline
\end{tabular}

Berdasarkan hasil pengujian pada tabel di atas, diperoleh nilai t hitung $>\mathrm{t}$ tabel atau $(10,745>1,986)$, dengan demikian hipotesis yang diajukan bahwa terdapat pengaruh yang signifikan atara budaya organisasi terhadap kinerja karyawan diterima.

\section{Pembahasan Hasil Penelitian}

\section{Kondisi Jawaban Responden Variabel Budaya organisasi}

Berdasarkan jawaban responden, variabel budaya organisasi diperoleh ratting score sebesar 3,493 berada di rentang skala 3,40 - 4,19 dengan kriteria baik atau setuju.

\section{Kondisi Jawaban Responden Variabel Kinerja Karyawan}

Berdasarkan jawaban responden, variabel kinerja karyawan diperoleh ratting score sebesar 3,796 berada di rentang skala 3,40 - 4,19 dengan kriteria baik atau setuju.

\section{Pengaruh Budaya organisasi Terhadap Kinerja Karyawan}

Budaya organisasi berpengaruh signifikan terhadap kinerja karyawan dengan persamaan regresi $\mathrm{Y}=12,482+0,729 \mathrm{X}$, nilai korelasi sebesar 0,742 atau memiliki hubungan yang kuat dengan kontribusi pengaruh sebesar 55,1\%. Pengujian hipotesis diperoleh nilai $\mathrm{t}$ hitung $>\mathrm{t}$ tabel atau $(10,745>1,986)$. Dengan demikian hipotesis yang diajukan bahwa terdapat berpengaruh signifikan antara budaya organisasi terhadap kinerja karyawan diterima.

\section{KESIMPULAN DAN SARAN}

1. Kesimpulan

a. Variabel budaya organisasi diperoleh ratting score sebesar 3,493 berada di rentang skala 3,40 - 4,19 dengan kriteria baik atau setuju.

b. Variabel kinerja karyawan diperoleh ratting score sebesar 3,796 berada di rentang skala 3,40 - 4,19 dengan kriteria baik atau setuju.

c. Budaya organisasi berpengaruh signifikan terhadap kinerja karyawan dengan persamaan regresi $\mathrm{Y}=12,482+0,729 \mathrm{X}$, nilai korelasi sebesar 0,742 atau kuat dan kontribusi pengaruh sebesar $55,1 \%$ sedangkan sisanya sebesar $44,9 \%$ dipengaruhi faktor lain. Uji hipotesis diperoleh nilai $t$ hitung $>\mathrm{t}$ tabel atau $(10,745>1,986)$. 


\section{Saran}

a. Perusahaan masih perlu menanamkan budaya organisasi yang lebih baik lagi mengingat dalam penelitian ini indicator inovasi dan keberanian mengambil resiko memiliki nilai rata-rata presentase terendah 584ndicator584 indicator lainnya. Oleh karena itu disarankan bagi PT. Tommindo Sinar Mulia dapat lebih memberikan kesempatan kepada karyawan untuk menyumbang ide-ide kreatif dalam bekerja, dengan cara memberikan kebebasan yang terpadu dalam setiap project yang diadakan. Karyawan juga harus dididik untuk berani menghadapi masalah-masalah yang timbul dalam pekerjaan, baik itu individu maupun kelompok.

b. Untuk indicato kinerja karyawan khususnya dalam indicator ketelitan hasil kerja memiliki nilai rata-rata presentase terendah indicator indicator lainnya yang terdapat pada penelitian ini. Dimana pada pelaksanaannya masih ada beberapa karyawan yang belum mampu bekerja secara cermat dan teliti. Oleh karena itu disarankan bagi PT. Tommindo Sinar Mulia untuk lebih memperhatikan kinerja karyawannya dengan cara memberikan pelatihan kerja yang diselenggarakan secara berkala. Sehingga hal tersebut dapat meningkatkan kinerja karyawan secara khusus dan perusahaan secara umum.

\section{DAFTAR PUSTAKA}

Abdullah, M (2014) Manajemen dan Evaluasi Kinerja Karyawan, Yogyakarta: Penerbit Aswaja Pressindo.

Algifari. (2015). “Analisis Regresi untuk Bisnis dan Ekonomi”. Yogyakarta: BPFE.

Arikunto, Suharsimi (2014). "Prosedur Penelitian Suatu Pendekatan Praktek". Jakarta: Rineka Cipta.

Bangun, Wilson. 2012. Manajemen Sumber Daya Manusia. Jakarta : Erlangga.

Dessler, G. (2006.) Manajemen Sumber Daya Manusia (Jilid II). Jakarta: Indeks.

Edi Sutrisno (2016). Manajemen Sumber Daya Manusia. Jakarta: Prenadamedia Group.

Gerry Dessler (2016) Human Resources Management, Prenticehall, London: International Inc. Handoko (2016) Manajemen Personalia dan Sumberdaya Manusia. Yogyakarta: BPFE.

Hasibuan, Malayu S.P. (2016). Manajemen Sumber Daya Manusia. Edisi Revisi. Jakarta: PT Bumi Aksara.

Ilham, D. (2014). Implementasi Nilai-Nilai Keagamaan pada Mata Pelajaran Umum dalam Upaya Peningkatan Akhlak Peserta Didik di MAN Malili Kabupaten Luwu Timur (Doctoral dissertation, STAIN/IAIN Palopo).

Ilham, D. (2019). Implementing Local Wisdom Values in Bride and Groom Course at KUA Bara SubDistrict, Palopo City. Jurnal Konsepsi, 8(1), 1-9.

Ilham, D. (2019). Menggagas Pendidikan Nilai dalam Sistem Pendidikan

Nasional. Didaktika: Jurnal Kependidikan, 8(3), 109-122.

Imam Ghozali (2017). “Aplikasi Analisis Multivariate Dengan Program SPSS”. Edisi Kelima. Semarang: Badan Penerbit Undip.

Jasmani, J., \& Sunarsi, D. (2020). The Influence of Product Mix, Promotion Mix and Brand Image on Consumer Purchasing Decisions of Sari Roti Products in South Tangerang. PINISI Discretion Review, 1(1), 165-174.

Kharis, Ismu Fadli (2011). "Studi Mengenai Impulse Buying dalam Penjualan

Luthans Fred (2014) Organizational Behavior, Ney York: McGraw-Hill, New York.

Mangkunegara, Prabu Anwar. (2016). Evaluasi Kinerja SDM. Cetakan ke tujuh, PT Refika Aditama: Bandung. 
Nickels, William G. dkk. 2012. Pengantar Bisnis. Jakarta : Salemba Empat.

Notoatmodjo, Soekidjo. 2015. Pengembangan Sumber Daya Manusia. Jakarta : Rineka Cipta

Robbins, P.S, \& Judge, A.T. (2003). Organizational Behavior. Jakarta: Salemba Empat.

Santoso, Singgih (2015). "Menguasai Statistik Multivariat". Jakarta: PT Elex Media Komputindo.

Sedarmayanti (2016) Manajemen Sumber Daya Manusia, Reformasi Birokrasi dan Manajemen Karyawan Negeri Sipil, Cetakan Kelima, Bandung: PT Refika Aditama.

Simamora, Henry. 2014. Manajemen Sumber Daya Manusia. Yogyakarta : STIE YKPN Yogyakarta

Simanjuntak, Payaman J. 2012. Manajemen Dan Evaluasi Kinerja. Jakarta : Lembaga Penerbit FEUI

Siswadi, Edi. 2012. Birokrasi Masa Depan. Bandung : Mutiara Press

Sudjana (2014) “Metode Statistika”, Bandung: Tarsido.

Sugiyono (2017), "Metode Penelitian Administrasi : dilengkapi dengan Metode $R \& D$ ". Bandung: Alfabeta.

Sularmi, L. (2019). Pengaruh Budaya Organisasi Dan Disiplin Terhadap Kinerja Karyawan Pada PT. Mega Perintis Tbk. JENIUS (Jurnal Ilmiah Manajemen Sumber Daya Manusia), 3(1), 124-140.

Sunarsi, D. (2019). Penerapan MSDM Strategis Dalam Upaya Meningkatkan Kemampuan Organisasi dalam menyongsong Revolusi 4.0. Jurnal Ilmiah MEA (Manajemen, Ekonomi, \& Akuntansi), 3(1), 221-233.

Suryabrata, Sumadi. 2014. Metodologi Penelitian. Jakarta: Rajawali Press

Sutrisno, S., \& Sunarsi, D. (2019). The Effect of Work Motivation and Discipline on Employee Productivity at PT. Anugerah Agung in Jakarta. Jurnal Ad'ministrare, 6(2), 187-196. https://doi.org/10.31955/mea.vol3.iss1.pp221-233

Tangkilasan, Hessel Nogi. 2012. Manajemen Publik. Jakarta: Grasindo.

Veithzal Rivai (2015) Manajemen Sumber Daya Manusia Untuk Perusahaan, Jakarta: Raja Grafindo Persada.

Wibowo (2015) Manajemen Kinerja, Jakarta: PT. Raja Grafindo Persada.

Wood, Derek dkk. 2012. Pola Budaya Organisasi. Jakarta: Inti Indayu

Zainal, Veithzal Rivai dkk. 2014. Manajemen Sumber Daya Manusia Untuk Perusahaan. Jakarta: Rajagrafindo. 